female, even in the time between two breeding periods, is not an exception but the rule in certain South American Cichlidæ.

In this connexion it is interesting to note that the blind cavernicolous Cichlids of south-west Africa are of the mouth-breeding type, where only one of the two sexes is charged with the care for the brood, and not of that 'father and mother family' type of family care which seems to have been able to play an important part in the acceleration of species formation in loco in the Cichlidæ of the great East African lakes.

Department of Zoology,

University of Istanbul. Feb. 5.

${ }^{2}$ Worthington, E. B., "Geographical Differentiation in Fresh Waters with Special Reference to Fish", in "The New Systematics" (ed. by J. Huxley) (Oxford University Press, 1941).

' Kosswig, C., "Kontinentalverschiebungstheorie und Fischverbreitung", C.R. Soc. Turque Sci. phys. nat., 11, 5 (1944).

\section{Feeding Mechanism of Water-Bugs}

THE suggestion put forward by Walton ${ }^{1}$ that the presence of small teeth and chitinous elevations in the pharynx of Micronecta indicates that this Hemipteran ingests and masticates particulate food material appears to be true for other families of the Cryptocerata. There exists in many, and probably all, species of Corixidæ a type of feeding mechanism which does not seem to have been recorded. This takes the form of a modification of the cibarial suction pump ${ }^{2}$ in such a manner as to produce a pair of chitinous jaws having a structure and position strongly suggesting that they function as organs for the comminution of solid material. It is a mechanism more elaborate in form than that found in Micronecta. The whole ventral wall of the cibarial pump consists of a curved chitinous plate having a thickened posterior margin. The anterior border of this plate appears to be folded back and modified into a transverse triangular bar set with rows of minute tooth-like projections. Above this bar and articulating with it at its lateral ends lies a second chitinous bar formed by the thickened dorsal wall of the cibarium and similarly equipped with teeth or rugosities (Fig. 1). The two bars have the appearance of a pair of grinding jaws, and although the musculature of the organ has not been studied in detail, enough has been noted to support this supposition.

Some variation during the life-cycle in the importance of this mechanism for the grinding of food particles may exist, as in early instar nymphs (Fig. 2) the toothed surfaces are distinct, whereas in the imago, while the ventral plate and jaws are more heavily chitinized, the teeth appear to be less pronounced.

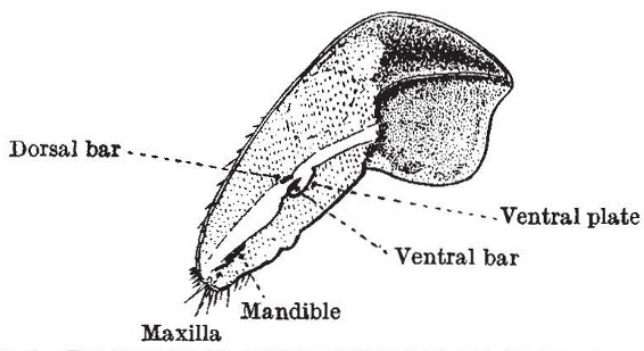

Fig. 1. Diagrammatic longitddinal section of the Head of Sigara striata TO SHOW DISPOSITION OF SCLERITES IN THE CLBARIAI

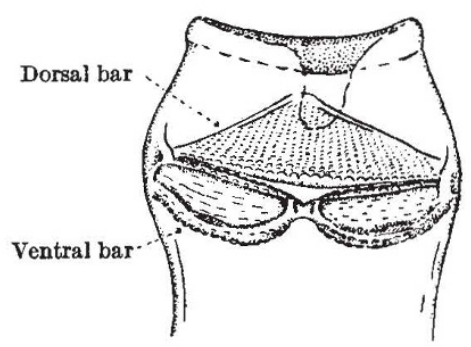
Fig. 2. DORSAL VIEW OF CIBARIAL PUMP IN NYMPH OF Sigara

The twelve species of Corixa, Sigara, Clanocorisa and Cymatia so far examined all show the structure with only minor variations in form between the species. A somewhat similar organ is present also in Notonecta, where, however, the teeth are replaced by bristle-like projections; in this family it may serve as a filter.

This is thought to be a type of food ingestion unique in the Hemiptera, and further investigation of the mouth parts and feeding in Corixidæ and Notonectidæ is being made for publication at a later date.

Department of Zoology,

University of Glasgow.

1 Walton, G. A., Trans. Soc. Brit. Ent., 5 (7), 268 (1938).

"Snodgrass, R. E., "Principles of Insect Morphology" (New York, 1935).

\section{Effects of High Temperature and Short Days on Vernalization Response of Summer Varieties of Rice}

THE effect of high temperature on the acceleration of flowering in a number of varieties of rice has been reported previously ${ }^{1,2,3,4}$. In addition to early flowering, pre-sowing high-temperature treatment results in better resistance to drought conditions ${ }^{5}$. Vernalization by high temperature has practical difficulties. Radicles and plumules emerge from the seed coat during treatment, involving difficulty of transportation. This has been overcome in two varieties of rice noted below by limiting the moisture content of seeds to 30 per cent of fresh weight. Seeds at this moisture content germinated without the radicles and plumules penetrating the seed coat, and gave vernalization response when exposed to high temperature, $35^{\circ} \mathrm{C}$., for 10 and 20 days (see table).

As regards the effects of day-length on flowering, a marked contrast between summer (Aus) and winter (Aman) varieties of rice has been noted by us. In previous communications in Nature ${ }^{6,7}$, acceleration of flowering of winter varieties by short days has been reported by one of us, and this has been confirmed". On the other hand, the effect of short days on summer varieties is different. The following results (see table) show that short days delay flowering and annul the effect of vernalization by high temperature. Presowing high-temperature treatment accelerates flowering; but when this is followed by short-day exposure of seedlings, a reverse effect in the delay in flowering is noticed.

In the light of these findings, Kar's statement" that in different varieties of paddy warm temperature associated with short day-length is inducive to earliness, and cold temperature or longer day-lengths produces retardation, needs modification. In the 